\title{
Relevance of HIV IEC Materials-A study among PLHIVs
}

\author{
Ms. Pratheepa C.M ${ }^{1}$ and Ms. Nithya. $\mathrm{K}^{2}$ \\ ${ }^{1}$ (Lecturer, PG dept. of Social Work, Holy Cross College, Nagercoil, India) \\ ${ }^{2}$ (Research and Documentation Officer, Pro-Vision, Nagercoil, India)
}

\begin{abstract}
AIDS has been the leading cause of death in world wide. India has a population of around 2.5 million people living with HIV/AIDS, aged between 15 and 49. For the enhancement of the quality of life of the People living with HIV more projects were carried out by Govt. and Non Government Organizations. Information, Education and communication (IEC) is an integral part in these projects. This paper reveals the relevance of IEC materials published under the project of Prevention of HIV/AIDS and Strengthening of PLHA Self-help Network in Tirunelveli District.

Descriptive methodology was adopted for the study. Both Quantitative and qualitative data were collected by using interview method and focused group discussions. There are five NGOs involved in the study and 122 PLHIV interviewed with Systematic sampling method. The study reveals 97.5 per cent of the target people received IEC materials. 86.9 percent of them have read the materials. Within this 64.8 percent of them adopted few matters they read in their life. 81.1 percent of them responded that the IEC materials were easy to understand. Finally this study concluded that the IEC materials were very useful for the target people because 91.8 per cent wished to continue the IEC materials even after completion of the project.
\end{abstract}

Key words: IEC material, Impact of IEC, People Living with HIV/AIDS, Quality of life, Self- help network

\section{Introduction}

HIV/AIDS remains un-curable, marginally treatable, and yet completely preventable. The government and the non-governmental organizations implement various programmes and projects to enhance the Quality of Life of the Persons living with HIV/AIDS (PLHIVs). The major focus of NGO activities have been awareness raising for prevention of HIV and extending care and support to the PLHIV and their family members by reducing the stigma and discrimination and facilitating access to available services. In all these activities the role played by Information, Education and Communication (IEC) materials is tremendous. IEC become effective only when they are relevant, need based and used by the targeted audience.

In Tirunelveli District HIV/AIDS intervention were carried out in different aspects. Since 2007 a networking organization 'Pro-Vision' co-ordinate four NOGs that is Arumbugal Trust, Peace Trust, Centre for People's Education and Aussi CODES to implement the projects of HIV/AIDS. To facilitate the activities of Pro-Vision network towards sustainability, IEC materials were published in the form of Newsletters, Booklets and pamphlets based on the needs of the target people. The present study conducted to know the effectiveness of the publications through a participatory internal assessment with the following objectives.

1. To identify the reach of IEC materials and its contents among the target people.

2. To consolidate the feedbacks of people about the content, design and size of the IEC.

3. To know the impact created by IEC on the target people.

\section{Research Methodology}

Since the study wants to describe the receiving, reading, sharing and practicing the read information of the IEC materials the descriptive research design was adopted for the study. The data were collected from the 4 networking NGOs of Pro-Vision with the help of Interview schedule and Focused group discussion guide. Systematic sampling method was applied and $10 \%$ of PLHIVs (ie, 122 PLHIVs) under the care of these NGOs gave information. Also five Focused Group Discussions were conducted in support groups with 40 members for getting more details on IEC materials. The data were analyzed with the help of SPSS.

\section{Socio demographic details}

Knowing the socio demographic details of the respondents clarify the nature of study group. Here there were 57.4 percent of the respondents belongs to 30-39 age group and 27 percent of them were within $40-49$ age groups. The respondents from 20-29 age groups were less that is 7.4 percent. On analyzing the sex of the respondents $54.1 \%$ of them were female remaining $45.9 \%$ percent was male. Fig 1 depicts the education details of the respondents. 


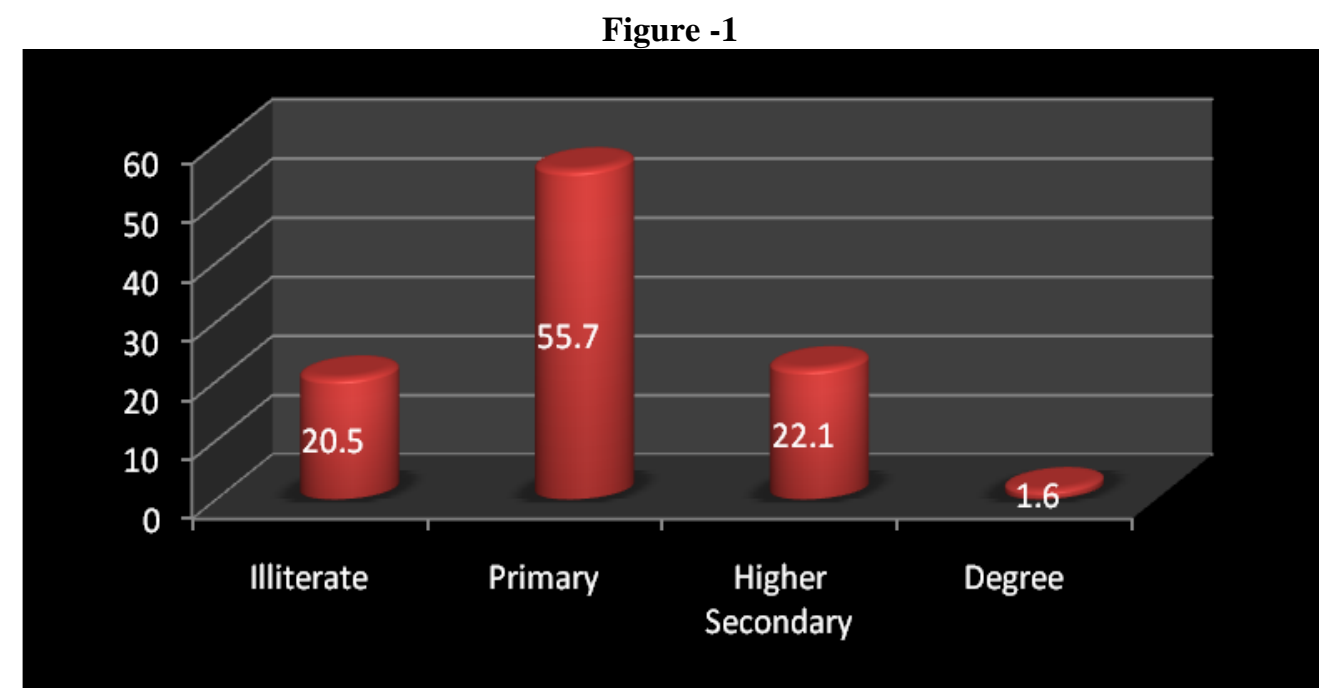

\section{Education of the respondents}

While analyzing the occupation of the respondents 78.7 percent of the respondents were working as daily coolies and 4.1 percent of the respondents were agriculture coolies. PLHIVs who in Government job were 4.9 percent and few $(3.3 \%)$ do business.

\section{Reach of IEC materials and its information among the target people}

IEC is the process of learning that empowers people to make decisions, modify behaviors and change social conditions. This part of analysis reveals the reaching of the IEC materials to the PLHIVs and their further discussion on the information given in these materials.

\subsection{Types of publication received}

Aiming towards sustainability 13 Nellai Sutram (NS) Newsletters, 3 Booklets and a few pamphlets were published based on the needs of the target people. The analysis indicates that 98.3 percent of the respondents received Nellai Sutram Newsletter which is a quarterly focusing on personal sharing of NS members, status of Nellai Sutram, Sharing of NGO representatives to help to reduce the self stigma and the social stigma among the target people.

Also 'Nam Kudumbathil Oruavar' booklet reached 72.9 percent of the respondents which is prepared to facilitate home based care by the family members of PLHIVs. 'Theringugonga Purinchugonga Nadanthugonga' was published for general people containing the basic information on HIV/AIDS were received by 59.8 percent of the respondents.

'HIV yudan Valvor Valkkai Tharam Membada Muraiyana Sigitchai' is a training manual aiming at accessing and adherence to ART Treatment and timely treatment seeking for opportunistic infections and 'HIV yudan Valvor Sirappu Thevai Kaiyaluthal' booklet with the objective of identifying the specific needs of special categories like PLHIV with TB, concordant couples, discordant couples, widows and care takers of children with HIV are also received by the respondents in a remarkable percentage.

Further the handbill 'Nam Valkkai Nam Kaiyil for the PLHIV to facilitate ART adherence was received by half of the respondents and Valkkai Payanathil' handbill for safe migration reached the respondents in a least level than other IEC materials. The below table indicates the percentage of the reach of these materials to the target people.

\section{TABLE - 1}

DIFFERENT TYPES OF PUBLICATION RECEIVED

\begin{tabular}{rlrr}
\hline SI.NO & DIFFERENT TYPES OF PUBLICATION & FREQUENCY & PERCENT \\
\hline 1. & Nellai Sutra Newsletter & 720 & $\mathbf{9 8 . 3}$ \\
2. & Theringukonga Purinchukonga Nadanthukkonga & 69 & 59.8 \\
3. & HIVudan Valvoor Valkkai Tharam Membada Muraiyana Sigitchai & 50 & 56.5 \\
4. & Valkkai payanathil & 62 & 50.9 \\
5. & Nam Valkai Nam Kail & 89 & $\mathbf{7 2 . 9}$ \\
6. & Nam Kudumbathil Oruvar & 70 & 57.3 \\
7. & HIVudan valvor sirappu thevaikalai kaiyaluthal & & \\
\hline
\end{tabular}




\subsection{Source of Receipt}

There are a lot of source contributed to receive the IEC materials. Here the analysis observes that 90.2 percent of the respondents received the IEC materials from Home Based Care Facilitators and 62.5 percent of them got through Support Group Facilitators. From the care givers 35.2 percent of PLHIVs received the needed IEC materials. Only 20.5 percent of the respondents received from other staffs in the project.

\subsection{Readability, Sharing and Practice of read information}

It has been observed that all the IEC materials published by the networking organization were read by 29.5 percent respondents. More than half percent $(57.4 \%)$ of the respondents have read few IEC materials. Remaining 13.1 percent of the respondents didn't read any publication. Among this most of them were uneducated. Some of the uneducated support group members shared that they read the materials with the help of their children and family members.

On analyzing the sharing of IEC materials by the respondents, 48.4 percent of them were sharing a few matters only. 12.3 percent of the respondents were sharing all matters read. Within 12.3 percent, female PLHIVs share more information than male. While analyzing the age of the respondents above 50years PLHIVs percentage was high in sharing all information which they read from IEC materials. Majority of the respondents (41.8\%) shared the read information to their neighbors and 29.5 percent respondents shared with support group members. The remaining respondents shared with their friends and family members. From this it is clear that the process of sharing facilitated to create awareness about HIV/AIDS and increase community acceptance.

With regard to the respondents adopting what they read, 64.8 percent of respondents adopted few matters in their life. Majority of the people responded they were following ATR adherence and personal hygiene.

Figure - 2

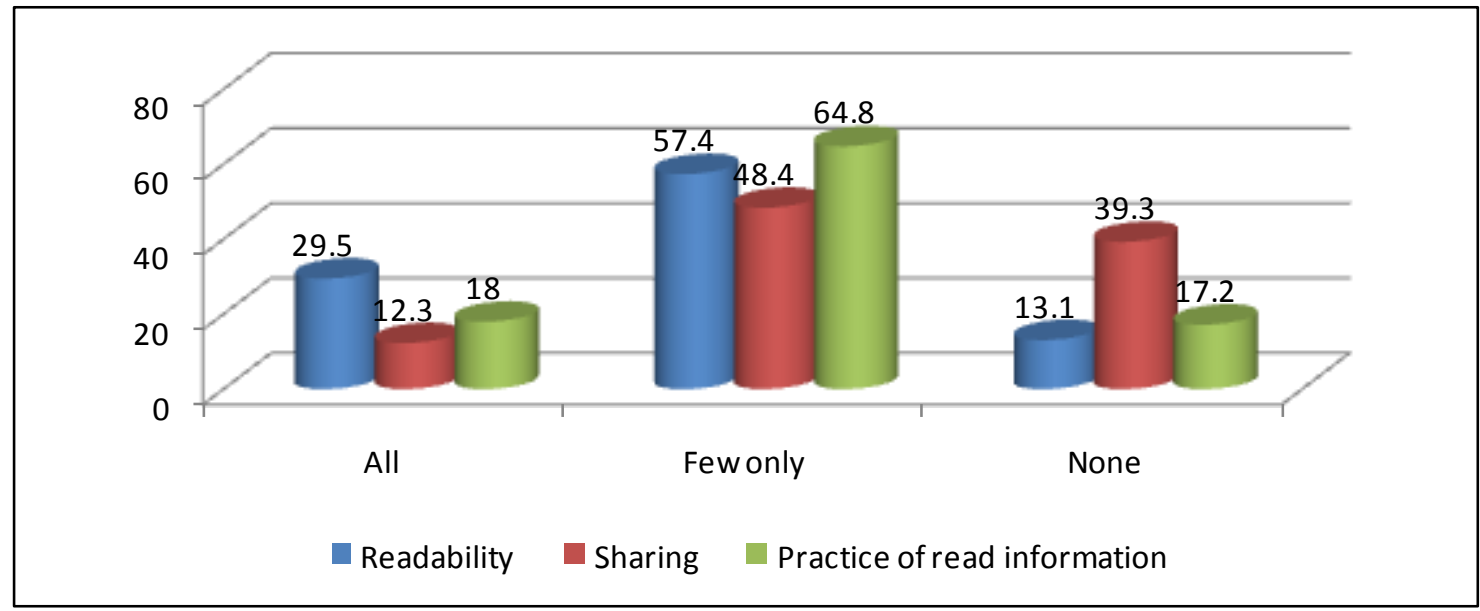

Readability, Sharing and practice of read Information

\subsection{Motivating to read others}

The effective reading of IEC materials encourages others to read. The analysis shows that 69.7 percent of the respondents were not interested to motivate their friends and others to read IEC materials. 5.7 percent of the respondents always motivated others to read the IEC materials. FGD with PLHIVs reveals some of the support group members encouraged the other members to read IEC materials as they got benefited from those materials.

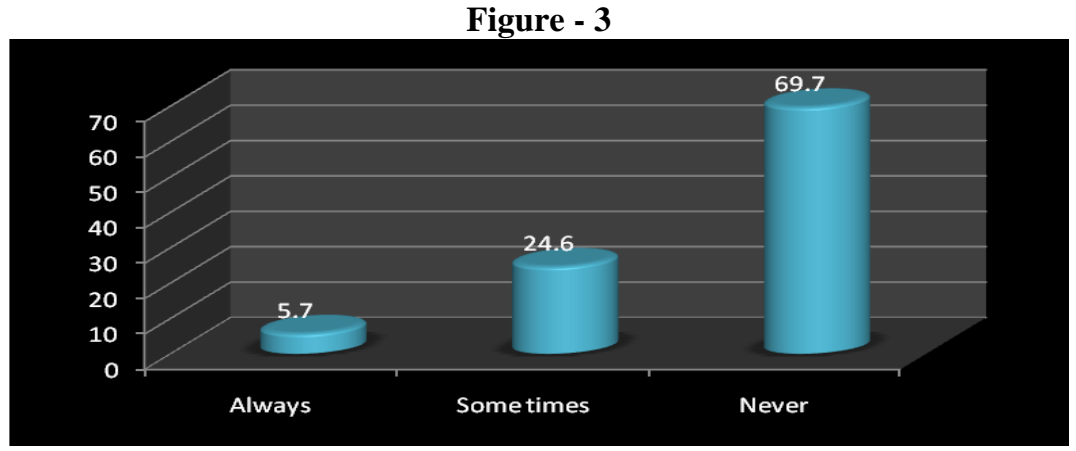




\section{Motivating others to read}

From the above analysis it is clear that the members who are actively involved in support group access the IEC material and the needed information. But the sharing of that information with others was less. Also the uneducated PLHIVs relay on the family members or others to read the information of IEC materials.

\section{Feedback of people about the color, content and size of the IEC}

IEC materials could affect more changes in the community if they are prepared properly and well used by the community. For the effective implementation of IEC materials the feedback were collected from the respondents regarding the color, understandability and need of further materials.

\subsection{Color}

Color of the reading material usually attaract the people to show intrest to read the material. The analysis of the present study shows that $84.4 \%$ of the respondents stated that the colour of the publications was fair and 6.6 percent of the respondents stated it was not good. It has been concluded that majority of the respondents liked the colors of the publications.

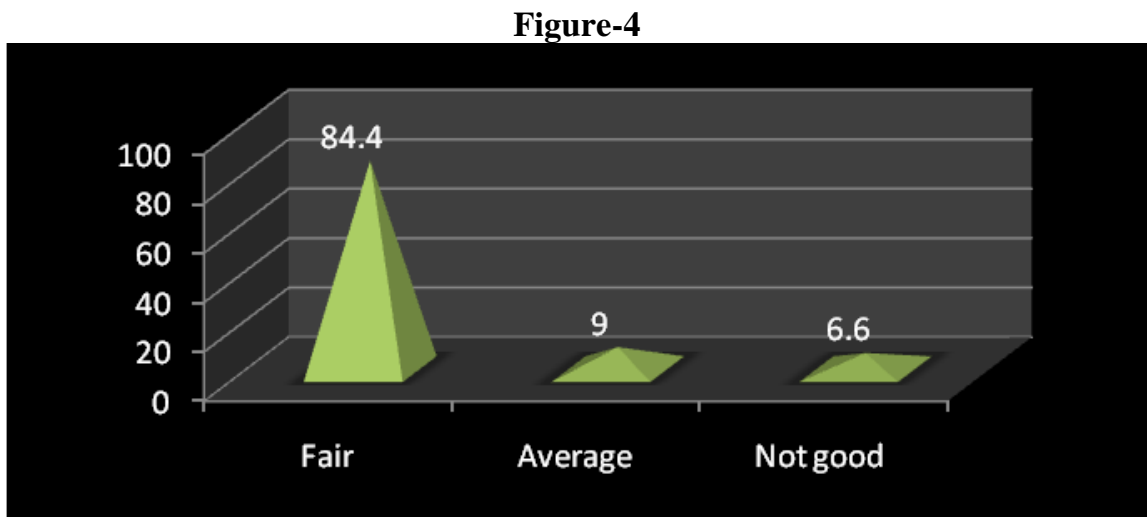

Opinoin of colours

\subsection{Understandability}

Simple and understandable words motivate the readers to continue the reading. It has been observed from the study 81.1 percent of the respondents felt that the IEC materials were easy to read. Only 5.7 percent of the respondents felt they were tough to read. According to the FGD results majority of the persons told that they were easy to read but they expressed that the size of the letters could be bigger

\subsection{Need to continue the IEC materials}

The need of the continuation of the relevant publication of IEC materials also analyzed. The study indicates that $91.8 \%$ of the respondents wish to continue the IEC materials after completing the project. Most of them like to get the Nellai Sutram Newsletters. FGD reveals that it was useful to get community contribution and also to reduce the self stigma.

\subsection{Most liked publication}

It has been observed that the most liked publication was Nellai Sutram Newsletter ( $87.7 \%)$. Most of them told that they were eagerly waiting for the newsletter and their friends and neighbors also read it regularly. The second place was occupied Nam Kudumbathil Oruvar booklet. 32.7 percent of the respondents opinioned that it was very useful for home based care and to improve personal hygiene. The least place was hired by 'HIVudan Valvoor Valkkai Tharam Membada Muraiyan Sigitchai'.

The summary of the feedback of the people expresses that the nature and the content of the IEC materials were mostly liked by the PLHIVs and it is useful for them.

\section{Impact created by IEC on the target people}

Modifying the behaviors and changing the existing social condition is the great achievement of IEC materials. The PLHIVs who were under the home based care of the NGOs adopted some good practices by the influence of IEC materials. 


\subsection{Different practices adopted}

Treatment adherence was a challenging one for the PLHIVs when they were in a closed wall. Intervention of home based care broken this barrier and bring them out to seek treatment for their illness. The FGD with PLHIVs reveals that the IEC material played an important role to increase the treatment seeking behavior, know the availability of treatment and its source, self care and responsibility to manage the life, utilizing the available government scheme and confidence to lead life.

It has been indicated in the below table that 65.57 percent of the respondents adopted ART adherence. Remarkable percent of them (36.88\%) were using boiled water every day and 27.04 percent of them having nutritious food regularly. Some of the support group members shared that they have adopted safe practices and prevented further transmission of HIV. They also took efforts to overcome associated factors like alcoholism and use of tobacco.

\begin{tabular}{|c|c|c|c|}
\hline \multirow[b]{2}{*}{ NO } & \multicolumn{3}{|c|}{$\begin{array}{c}\text { TABLE }-2 \\
\text { DIFFERENT PRACTICES ADOPTED }\end{array}$} \\
\hline & DIFFERENT PRACTICES ADOPTED & FREQUENCY & PERCENT \\
\hline 1. & Usage of Condom & 18 & 14.75 \\
\hline 2. & ART Treatment Adherence & 80 & 65.57 \\
\hline 3. & Usage of boil water & 45 & 36.88 \\
\hline 4. & Participate the Support group meeting & 22 & 18.03 \\
\hline 5. & Personal Hygiene & 31 & 25.41 \\
\hline 6. & Nutritious Food & 33 & 27.04 \\
\hline 7. & Care of family members & 7 & 5.73 \\
\hline 8. & Treatment for opportunity infections & 26 & 21.31 \\
\hline 9. & Environment cleanliness & 4 & 3.27 \\
\hline
\end{tabular}

\subsection{Recognition to contribute}

Contribution to the IEC materials in the form of message, message with photo paves the way to increase the recognition in the society and among friends shared by 5.7 percent of the respondents who contributed messages with photo. Also the self stigma and social stigma has reduced by Nellai Sutram News letter. But during FGDs those who did not share any information stated that since they have girl children they were not interested to share their HIV status and not seeking recognition on their HIV status.

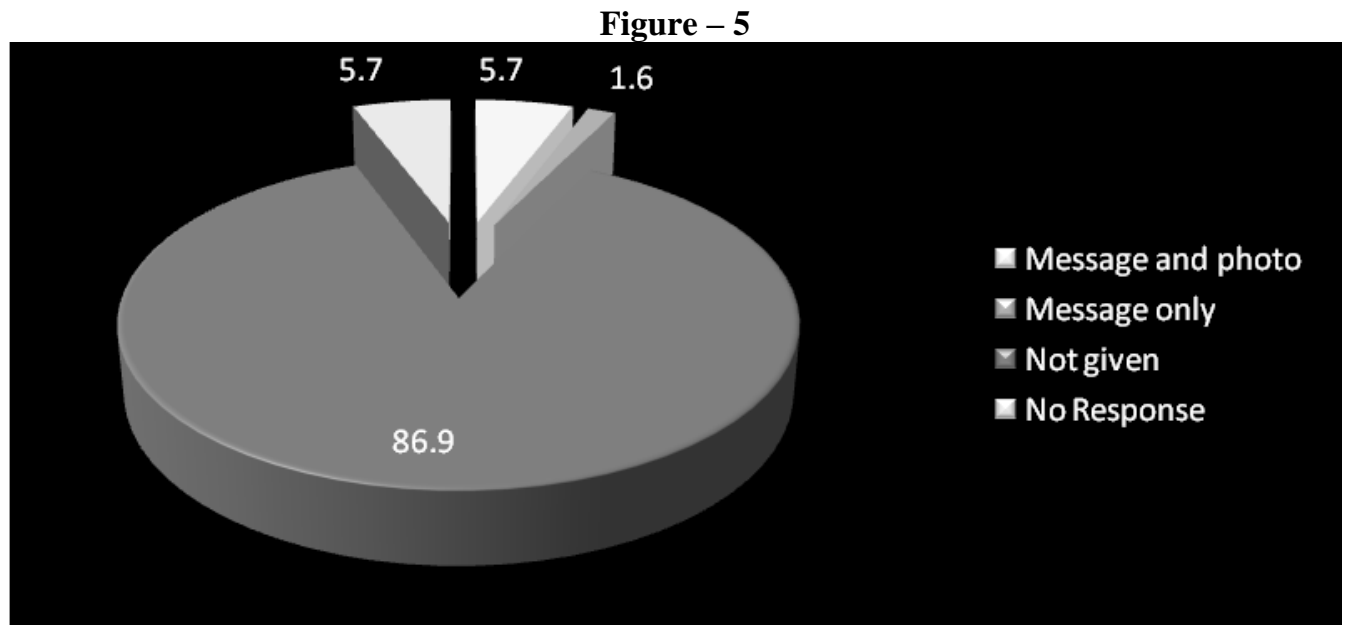

Matters contributed to Nellai Sutram News Letters

From the impact of IEC material analysis it is understood that the published IEC materials made changes among the PLHIVs to follow ART treatment adherence and safe practices to prevent further transmission and opportunistic infections. Also the IEC materials gave chances to the PLHIV s to create identity and acceptance among the public by writing messages in the name of the PLHIVs and their experiences. Another way it has reduced the self stigma and induced to achieve the desired goal of the PLHIVs.

\section{Important Findings}

- Nellai Sutram News Letter and Nam Kudumbathil Oruvan booklet was received by majority of the PLHIVs.

- Home Based Care Facilitators plays an important role to issue the IEC materials to PLHIVs. 
- Only 29.5 percent of the respondents read all the IEC materials received by them. Some illiterate persons sought the help of their children and family members to understand the IEC.

- Nellai Sutram news letter was most liked (87.7 \%) IEC material among the publication of networking organization. It was also very useful to get community contribution.

- Nam Kudumbathil Oruvan booklet was very useful for home based care. 48.4 percent of the respondents shared few matters they read with others. 64.8 percent of them adopted few matters they read in their life.

- 81.1 percent of them responded that the IEC materials were easy to understand.91.8 percent wished to continue the IEC materials even after completion of the project.

- The readers adopted various practices by IEC material. Among this ART adherence and following safe practices to prevent opportunistic infection and HIV transmission are most highlighted practices.

- $\quad 5.7$ percent of the respondents contributed to Nellai Sutram News letter either only message or message with photo. Community acceptance increased and self stigma decreased through the messages of IEC materials.

\section{Suggesions}

1. Planned efforts should be taken to increase the membership in support groups. The officer bearers and members of the existing support groups could play a dynamic role in motivating the non members to become members of support groups.

2. The project staffs should ensure that all the PLHIV under HBC receive all the IEC materials promoted by the project. In addition they should also take efforts to make sure that all those who received the IEC also read and understand the content of it. The follow up visit to the PLHIV by the HBC facilitators should use the content of IEC as the base for further interaction and motivation. This will motivate them to read them more seriously.

3. The support group facilitators and the support group leaders should take efforts to read the all IEC materials in support group meeting. There could be focused discussion based on the contents of the IEC read in the group. The doubts arising out of the reading could be clarified and applied to individual cases as well.

4. Stigma being identified as a major factor to be addressed through IEC, more hand bills should be published to facilitate reduction of self stigma and social stigma. The publication should be attractive and contain sufficient information to address self and social stigma.

5. The PLHIV should not only read the IEC but also should take efforts to share the materials to their friends and neighbors. Thus they could facilitate awareness creation and reduction of social stigma and mobilize community support.

6. As majority of them have lower level of literacy and some of them have difficulties in reading, as far as possible, the fond size should be bigger and easily visible.

7. Home based Care facilitators should help the illiterate persons to listen to and understand the contents of IEC relevant to them.

\section{Conclusion}

Promotion of IEC is an integral part of the project on "Prevention of HIV/AIDS and Strengthening of PLHIV Self-help Network" and a number of IEC were promoted. It is also the responsibility of the project to make these IEC more relevant and people friendly. This study definitely will contribute towards the attainment of the project goals by promoting relevant and need based IEC materials.

\section{Acknowledgement}

It's our privilege to express our gratitude to Dr. Johnson Raj, Chief Executive, Pro-Vision for the technical support. Also we acknowledge our gratitude to the Director and staff of the partner NGOs for their valuable support to interact with the PLHIVS and to collect data. We extend our heartfelt thanks to PLHIVs who cooperate with us to finish the study successfully.

\section{Reference}

[1]. http://ejhd.uib.no/ejhd-v22-n3/232\%20Effectiveness \%20of \%20IEC\%20interventions \%20in\%20reducing\%20HIV\%20AIDS\%20.pdf

[2]. http://www.pfpi.org/iec_std-hiv-aids.html

[3]. http://www.ksacs.in/iec-ksacs.php

[4]. http://www.google.co.in/url?sa=t\&rct=j\&q=\&esrc=s\&source=web\&cd=5\&cad=rja\&ved=0CEsQFjAE\&url=http\%3A\%2F\%2Fwww.c ncs.org.mz\%2Findex.php\%2Fpor\%2Fcontent $\% 2$ Fdownload\%2F1637\%2F14

[5]. http://www.sciencedirect.com/science/article/pii/S0955395905000800

[6]. http://www.icmr.nic.in/annual/mrc/2003-04/54-57.pdf 